\title{
Vertical and horizontal migrations by the jumbo squid Dosidicus gigas revealed by electronic tagging
}

\author{
W. F. Gilly ${ }^{1, *}$, U. Markaida ${ }^{2}$, C. H. Baxter ${ }^{1}$, B. A. Block ${ }^{1}$, A. Boustany ${ }^{1}$, L. Zeidberg $^{1}$, \\ K. Reisenbichler ${ }^{3}$, B. Robison ${ }^{3}$, G. Bazzino ${ }^{4}$, C. Salinas ${ }^{4}$ \\ ${ }^{1}$ Hopkins Marine Station, Department of Biological Sciences, Stanford University, Oceanview Boulevard, Pacific Grove, \\ California 93950, USA \\ ${ }^{2}$ El Colegio Frontera Sur, Laboratorio de Pesquerías Artesanales, Calle 10 No. 231, Campeche 2400, Mexico \\ ${ }^{3}$ Monterey Bay Aquarium Research Institute, 7700 Sandholdt Road, Moss Landing, California 95039, USA \\ ${ }^{4}$ Centro de Investigaciones Biológicas del Noroeste, Mar Bermeijo No. 195, Col. Playa Palo de Santa Rita, La Paz,
} Baja California Sur 23090, Mexico

\begin{abstract}
Dosidicus gigas is a large and powerful oceanic squid that is economically valuable and ecologically important in the eastern Pacific Ocean. We employed electronic tagging methods to provide the first long-term monitoring of the natural behaviors of D. gigas in its mesopelagic habitat. Seven pop-up satellite tags logged depth and temperature for a total of $842 \mathrm{~h}$, and a conventional archival tag yielded $780 \mathrm{~h}$ of continuous time-series data. Horizontal movements of nearly $100 \mathrm{~km}$ over $3 \mathrm{~d}$ were observed, and these were temporally associated with an established transGulf migration. Squid consistently spent most daylight hours at depths $>250 \mathrm{~m}$, the approximate upper boundary of a midwater hypoxic zone termed the oxygen minimum layer (OML). A diel migration brought squid to near-surface waters at dusk, but a highly variable amount of diving back into the OML occurred throughout the night. Rhythmic vertical movements within the OML often occurred, and sojourns of up to $6 \mathrm{~h}$ in this hypoxic zone below $300 \mathrm{~m}$ were observed. Laboratory experiments revealed a high resting rate of oxygen consumption under normal conditions, but this rate decreased drastically under hypoxic conditions such as would be associated with the OML in nature. These findings suggest that $D$. gigas has physiological adaptations that permit constant foraging in both oxygenated near-surface waters and within the OML.
\end{abstract}

KEY WORDS: Squid · Electronic tagging · Oxygen minimum layer · Migration · Diving · Hypoxia · Gulf of California

Resale or republication not permitted without written consent of the publisher

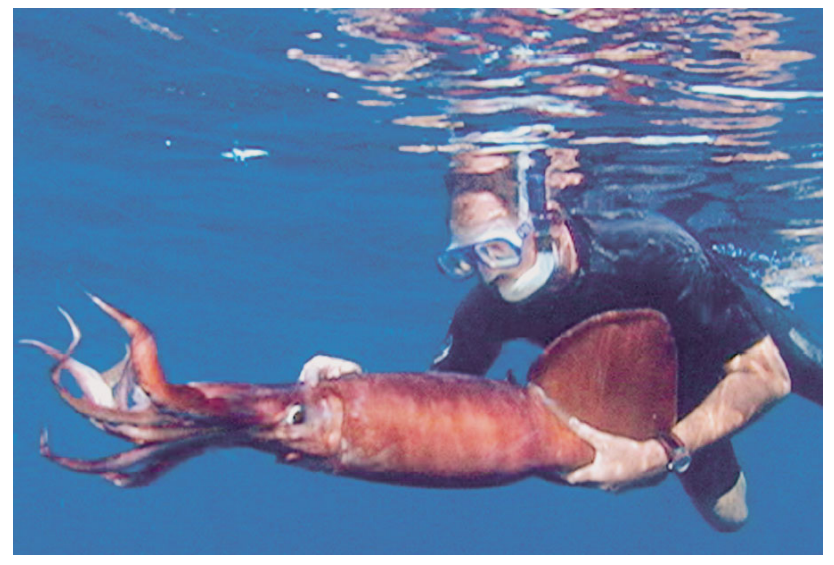

Oceanic squids such as Dosidicus gigas (photo) provide a critical link between lower trophic levels and apex vertebrate predators. The first electronic archival-tagging study of $D$. gigas reveals that it regularly inhabits cold, hypoxic midwater depths and that it remains remarkably active in this hostile environment.

Photo: Bob Cranston (courtesy of National Geographic Television)

\section{INTRODUCTION}

Ommastrephid squids are migratory predators of the open ocean and are ecologically and economically important on a global scale. Dosidicus gigas (jumbo or Humboldt squid), the largest ommastrephid (up to $50 \mathrm{~kg}$ mass and overall length of $2.5 \mathrm{~m}$ ), is endemic to the eastern Pacific, particularly the highly productive waters of the California and Peru Current systems 
(Nigmatullin et al. 2001) and the Costa Rica Dome (Ichii et al. 2002, Waluda \& Rodhouse 2006). This species is the target of the world's largest cephalopod fishery, with landings of $8 \times 10^{5}$ metric tonnes ( $\mathrm{t}$ ) in 2004 (FAO data at ftp://ftp.fao.org/fi/stat/summary/a1e.pdf). A substantial fraction ( 15\%) of this catch comes from the Guaymas Basin in the Gulf of California, Mexico, a relatively small area where commercial fishing is centered around the ports of Santa Rosalia, Baja California Sur, and Guaymas, Sonora. This fishery targets jumbo squid that mature at a large size of 50 to $75 \mathrm{~cm}$ mantle length (ML) (Markaida \& Sosa-Nishizaki 2001).

Despite the economic importance of Dosidicus gigas, relatively little is known of its natural behaviors or life history. This squid is extremely fast growing, increasing from $1 \mathrm{~mm} \mathrm{ML}$ at birth to $1 \mathrm{~m}$ ML in a life-span of 1 to $2 \mathrm{yr}$ (Nigmatullin et al. 2001, Markaida et al. 2004). Clearly such a high growth rate requires a substantial dietary intake. Assuming a conservative body mass of $10 \mathrm{~kg}$, $10^{5} \mathrm{t}$ of $D$. gigas is equivalent to $10^{7}$ squid. With an individual daily consumption rate for large, mature squid of $\sim 10 \%$ body mass (Ehrhardt 1991), D. gigas of a size caught by the fishery in the Guaymas Basin would thus together consume at least $10^{7} \mathrm{~kg}\left(10^{4} \mathrm{t}\right)$ daily. In this region, prey consists of an assortment of mostly small mesopelagic organisms, including fishes, crustaceans and small squids (Markaida \& Sosa-Nishizaki 2003).

Dosidicus gigas is thus ecologically important as a major predator, but it is also vital as prey. As small juveniles these squid are undoubtedly preyed on by numerous pelagic fish and avian species throughout their broad range. In the Gulf of California adult squid serve as prey for both large fishes (Klimley et al. 1993, Abitia-Cardenas et al. 2002, Rosas-Aloya et al. 2002) and marine mammals, particularly sperm whales Physeter macrocephalus (Ruiz-Cooley et al. 2004). Thus, jumbo squid serve as an important trophic link between small mesopelagic organisms and top vertebrate predators.

In the Gulf of California Dosidicus gigas preys primarily on myctophids, small micronektonic lanternfishes (Markaida \& Sosa-Nishizaki 2003). These fish are an abundant component of the mesopelagic biomass in the Gulf, and they typically undertake a diel migration (Robison 1972), along with many other residents of the acoustic deep-scattering layer (DSL), from daytime depths of several hundred meters to near-surface waters at night. Commercial fishing for D. gigas is generally carried out at night, because this species, like other ommastrephids, is thought to undertake a similar diel vertical migration (Roper \& Young 1975, Nakamura 1991, 1993, Nigmatullin et al. 2001), thus making the squid more accessible at night.

Such a migration for an active squid like Dosidicus gigas presents a puzzle. Daytime depths associated with the acoustic DSL across much of the eastern Pacific encompass a midwater layer of oxygendepleted water (Dunlap 1970) termed the oxygen minimum layer (OML). This stable hypoxic zone typically extends from $\sim 250$ to $800 \mathrm{~m}$ in the southern half of the Gulf of California and results from microbial metabolism of sinking organic material generated by high surface productivity (Roden 1964, Alvarez-Borrego \& Lara-Lara 1991). Deep vertical migrations into the OML would thus bring $D$. gigas into an environment in which the dissolved oxygen level is only a few percent of the saturated value at the surface. All active, muscular squid thus far examined have exceptionally high respiration rates and cannot tolerate hypoxia, so their presence in the OML would seem to be precluded (Webber et al. 2000, Pörtner 2002).

Here we report the first long-term, electronic monitoring of the natural behavior of a pelagic squid. Large Dosidicus gigas individuals displayed rapid, longdistance horizontal migrations and complex vertical diving behaviors, with a large amount of time spent in the hypoxic OML. Respirometry measurements under laboratory conditions revealed that although $D$. gigas had a high rate of oxygen consumption under normal conditions, basal aerobic metabolism was greatly suppressed at dissolved oxygen levels characteristic of those in the OML.

\section{MATERIALS AND METHODS}

Electronic tagging. Two types of data-loggers were used-archival tags and pop-up archival transmitting (PAT) tags. Both devices sampled pressure and temperature every 2 to $4 \mathrm{~min}$. Depth resolution was scaled with depth, ranging from 1 to $4 \mathrm{~m}$ for archival tags and 1 to $16 \mathrm{~m}$ for PAT tags. Temperature resolution was 0.2 to $0.3^{\circ} \mathrm{C}$ for both types of tag. All tags yielding useful data were deployed on large Dosidicus gigas (>75 cm $\mathrm{ML}$ ) in the Gulf of California near Santa Rosalia during autumn (September to November). Local time ( $-7 \mathrm{~h}$ over Universal Time) was used throughout our analyses.

Adult squid were captured on the commercial fishing grounds with weighted, luminescent jigs (20 and $35 \mathrm{~cm}$ ) generally between dusk and midnight. Location of tag deployment was recorded with a handheld GPS unit (Garmin GPSMAP 76). Tagging methods evolved during the course of this study (2001 to 2005) and improved with experience. In particular, irrigation of the gills with flowing seawater during the tagging procedure, which typically took about 5 min, greatly improved the condition of the released squid. A tagged squid was released only if it displayed strong, rhythmic breathing during the tagging procedure and, whenever possible, it was held by 
hand just beneath the sea surface prior to release. Most tagged squid jetted strongly downwards immediately after release.

PAT tags: PAT tags actively release from the tagged subject at a programmed time by electrolysis of a metal pin, after which the tag floats to the surface and commences transmission of archived summary data to the Argos satellite system. These data include time-atdepth and time-at-temperature histograms (12 depth/ temperature bins, 1 to $2 \mathrm{~h}$ periods) and the maximum/ minimum depth/temperature for each period. Archival time-series data can only be obtained if the tag is physically recovered. Endpoint position of a tag is defined as the first reliable position determined by the Argos system (location quality $\geq 1$ ) after the tag releases and begins to transmit. Endpoint positions are generally available via internet within $1 \mathrm{~d}$ of release $(1.5$ to $27 \mathrm{~h}$ in the present study). Subsequent locations of a tag as it drifts are obtained in the same manner for 1 to $2 \mathrm{wk}$, until the tag's battery expires.

Geolocation of the tagged squid based on light level (also recorded by PAT tags) was not useful in the present study because the squid typically were deep in the water column during daylight hours. Even with corrections based on sea-surface temperature, resolution of these methods is not adequate for the relatively small distances covered in the present study (Teo et al. 2004).

We used 10 PAT tags (Wildlife Computers; PAT [2001; $\mathrm{n}=1$ ] and PAT 3.0 [2003 to 2005; $\mathrm{n}=9$ ]). Seven deployments were deemed successful as defined by the return of useful data acquired over at least $3 \mathrm{~d}$ (see Table 1). In addition, 2 unsuccessful deployments were made in 2003. In one case, the squid apparently died after less than $1 \mathrm{~d}$, and in the other, the tag never reported to Argos. Another tag was deployed in November 2005 and recovered about $1 \mathrm{~h}$ later by a commercial fisherman (see 'Discussion').

Tags were fixed to the ventral surface of a fin, adjacent to the mantle (Fig. 1A). The release pin was encircled by a loop of monofilament line (180 kg-test) secured by a plastic cable-tie to a nylon mounting bolt passing through the fin (Fig. 1B). The syntactic foam (float) end of the tag was loosely secured by another cable-tie that looped through the fin and passed through 2 slots in a button on the dorsal surface of the fin to minimize tissue damage. Tags were programmed to release after periods of 3 to $14 \mathrm{~d}$, but the longest successful attachment was $8 \mathrm{~d}$. Although some wear and tear on the fin is likely to be produced by the tag itself, it is more likely that premature detachment (see Table 1) of tags was due to attacks by other squid.

Archival tags: Archival tags (Lotek Wireless; LTD1100) must be physically recovered to access the

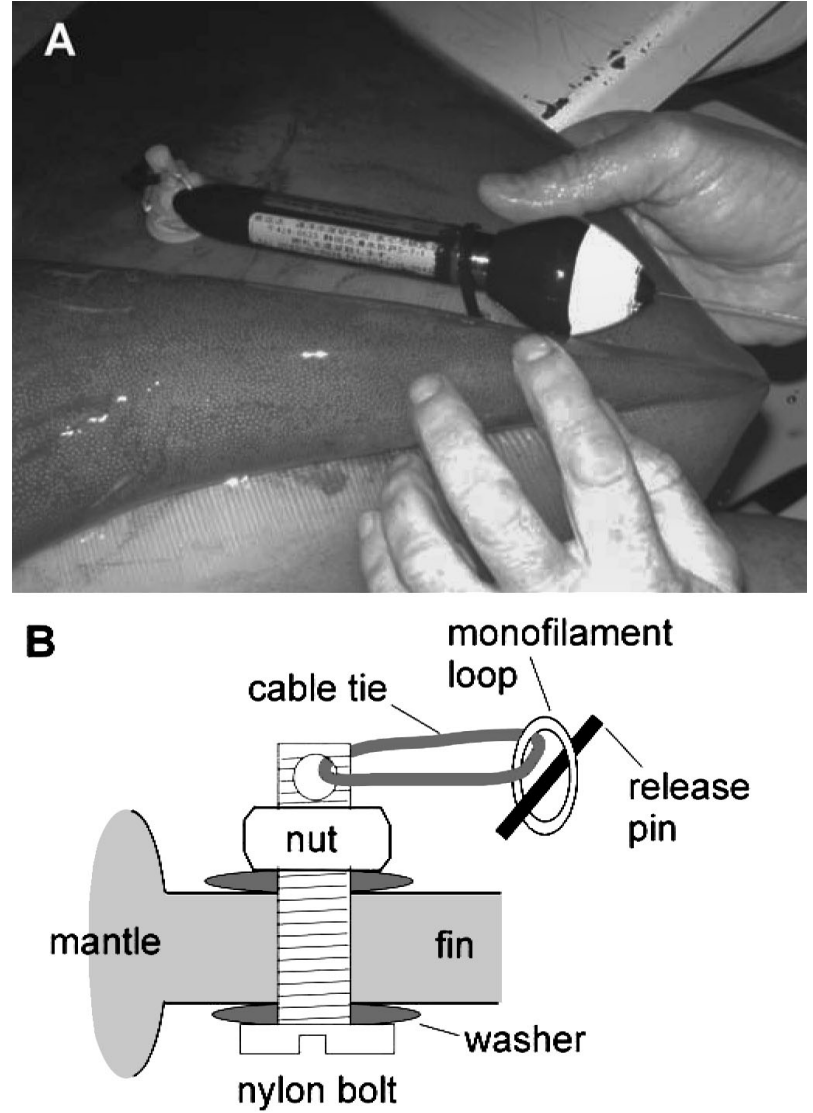

Fig. 1. Method of attachment for pop-up archival transmitting (PAT) tags. (A) Tags were attached to the ventral surface of a fin as illustrated with only the antenna protruding beyond the posterior edge of the fin. The anterior attachment assembly is on the left. The posterior cable-tie passed through a slotted button on the dorsal surface of the fin. (B) Detail of the anterior attachment site. Only the release pin portion of the tag is shown. See 'Materials and methods' for details

archived time-series data, and a local reward program was implemented to encourage returns. These tags were attached by 2 cable ties each looped through a $3 \mathrm{~mm}$ hole in the tag and then through the anterior edge of the dorsal mantle in a manner similar to that successfully used for conventional passive 'spaghetti' tags $(\geq 8 \%$ return rate in 3 independent experiments; (Markaida et al. 2005, and our unpubl. data).

A total of 96 squid (56 to $83 \mathrm{~cm} \mathrm{ML;} \mathrm{mean} \pm \mathrm{SD}=71.3$ $\pm 6.8 \mathrm{~cm}$ ) were tagged on 12 September, 2002, between 20:00 and 24:00 h. A single tagged squid (75 cm ML) was recovered off San Bruno, about $20 \mathrm{~km}$ south of the deployment site, at 21:45 h on 14 October. Based on the similarity of daily temperature-depth profiles experienced by this squid (data not shown), it is likely that this individual remained in the local area during this entire period. 
Oxygen versus depth profiles. Oxygen profiles were measured with a CTD profiler and oxygen sensor (Sea Bird Electronics; SBE19 with Beckman/YSI oxygen sensor) from the RV 'Marylee' (La Paz) at 6 sites on the Santa Rosalia fishing grounds in November 2005 within $2 \mathrm{~d}$ of deploying Tags 5 to 7 (see Fig. 2). Typically, we lowered the CTD to within about $20 \mathrm{~m}$ of the bottom while tracking it on the vessel's echosounder. All casts yielded similar profiles. Mean and SD values reported for oxygen concentrations were calculated from the 6 down- and 6 up-casts (i.e. $\mathrm{n}=12$ total).

Oxygen-consumption rates. Experiments were conducted in the Pacific Ocean off Monterey, California, on the RV 'Western Flyer' during cruises in March, June and September 2005. Dosidicus gigas specimens ranging in size (1.1 to $7.2 \mathrm{~kg}$ ) were captured at night by jigging, and squid were held individually in tanks plumbed with flow-through ambient seawater $\left(\sim 14^{\circ} \mathrm{C}\right)$ overnight. Individual squid were carefully transferred to an acrylic tank (250 l volume, plumbed with flow-through ambient seawater) in a walk-in cold room $\left(6^{\circ} \mathrm{C}\right)$. If the squid appeared calm and had not inked, the tank was then sealed and the water supply turned off. The decrease in dissolved oxygen concentration in the tank (due to squid respiration) was monitored with a temperature-compensated optode sensor (Aanderaa 3830). Generally, we then replaced the ambient seawater with chilled seawater, and carried out measurements at 6 to $7^{\circ} \mathrm{C}$. After respiratory activity had reduced the oxygen concentration to a pre-determined level, the tank was flushed with fresh, chilled seawater and the decline in oxygen was measured again. During these experiments, the squid was constantly monitored from outside the darkened cold-room via video using either dim, visible red or infra-red illumination.

\section{RESULTS}

\section{Long-distance horizontal migrations of Dosidicus gigas}

From fishery landings and conventional tag-andrecapture studies (Markaida et al. 2005), it is known that large Dosidicus gigas individuals migrate away from the fishing grounds off Santa Rosalia in the late fall, generally in mid to late November. It is thought that most squid migrate across the Gulf to fishing grounds off Guaymas, but details of the migration, including the times involved and routes taken, are not well understood. Substantial horizontal movements were therefore expected during most of our PAT tag deployments.

Deployment and endpoint locations for the 7 PAT tags that reported to Argos in the present study are indicated in Fig. 2 and Table 1. A squid tagged in September 2001 (Tag 1) appeared to move only a short distance, but the 3 tags in late October 2004 (Tags 2 to 4) surfaced at much greater distances from the deployment site. Tag 2 released from the squid on schedule after $7 \mathrm{~d}$ and surfaced in the Carmen Basin, almost $200 \mathrm{~km}$ away. Tag 4 first reported from even further in this southeast direction, and Tag 3 surfaced east of Santa Rosalia on the other side of the Guaymas Basin. These, latter 2 tags drifted for several days before reporting, because they detached from the squid prematurely. Exact endpoint locations are therefore unknown.

Of 3 squid tagged in mid November 2005 (Tags 5 and 6) 2 also traveled a considerable distance in the $3 \mathrm{~d}$ after tagging, but in this case migration was in a northerly direction. Tag 6 moved further, surfacing about $100 \mathrm{~km}$ to the north near the San Pedro Martir Basin. Although all 3 tags released on schedule

Table 1. Summary of PAT tag deployments. Endpoint date: last time of useful data-collection, i.e. when the tag either released on schedule or detached from the squid prematurely. Endpoint position: first location reported by Argos with a location accuracy code of $>1$. Distances (between deployment and endpoint locations) for Tags 3,4 and 7 are ambiguous and therefore not tabulated. Depth is the maximum recorded during the deployment

\begin{tabular}{|c|c|c|c|c|c|c|c|c|c|c|}
\hline \multirow[t]{3}{*}{ Tag } & \multirow[t]{3}{*}{ ID \# } & \multirow{3}{*}{$\begin{array}{c}\text { Mantle } \\
\text { length } \\
\text { (cm) }\end{array}$} & \multicolumn{3}{|c|}{$\longrightarrow$ Deployment $\longrightarrow$} & \multicolumn{3}{|c|}{$\longrightarrow$ Endpoint } & \multirow{3}{*}{$\begin{array}{l}\text { Depth } \\
\text { (m) }\end{array}$} & \multirow{3}{*}{$\begin{array}{l}\text { Distance } \\
(\mathrm{km})\end{array}$} \\
\hline & & & \multirow{2}{*}{$\begin{array}{c}\text { Date } \\
(\mathrm{mm} / \mathrm{dd} / \mathrm{yy})\end{array}$} & \multicolumn{2}{|c|}{ Position } & \multirow{2}{*}{$\begin{array}{c}\text { Date } \\
\text { (mm/dd/yy) }\end{array}$} & \multicolumn{2}{|c|}{ Position } & & \\
\hline & & & & $\left({ }^{\circ} \mathrm{N}\right)$ & $\left({ }^{\circ} \mathrm{W}\right)$ & & $\left({ }^{\circ} \mathrm{N}\right)$ & $\left({ }^{\circ} \mathrm{W}\right)$ & & \\
\hline 1 & 8891 & $\sim 85$ & $10 / 14 / 01$ & 27.34 & 112.21 & $10 / 20 / 01$ & 27.33 & 112.04 & 320 & 17 \\
\hline 2 & 52868 & 81 & $10 / 25 / 04$ & 27.34 & 112.22 & $11 / 02 / 04$ & 26.29 & 110.78 & 424 & 186 \\
\hline 3 & 52869 & 83 & $10 / 25 / 04$ & 27.34 & 112.22 & $11 / 02 / 04^{\mathrm{a}}$ & 27.43 & 111.01 & 428 & - \\
\hline 4 & 52865 & 77 & $10 / 26 / 04$ & 27.35 & 112.24 & $10 / 31 / 04^{\mathrm{a}}$ & 26.22 & 109.87 & 484 & - \\
\hline 5 & 62006 & 77 & $11 / 11 / 05$ & 27.30 & 112.17 & $11 / 14 / 05$ & 27.90 & 111.71 & 504 & 81 \\
\hline 6 & 62007 & 82 & 11/11/05 & 27.29 & 112.17 & 11/15/05 & 28.16 & 112.34 & 384 & 98 \\
\hline 7 & 62009 & 81 & $11 / 11 / 05$ & 27.29 & 112.17 & $11 / 15 / 05^{b}$ & 27.50 & 111.92 & $316^{\mathrm{c}}$ & - \\
\hline
\end{tabular}


Fig. 2. Location of the study area in the central Gulf of California showing deployment and endpoint locations of PAT tags (see also Table 1). (1) to (7) On main map: Locations of the first transmissions to Argos and corresponding tag number. A detailed view of the Santa Rosalia area is shown in the lower-left inset. $(\diamond)$ Deployment locations of PAT tags and respective numbers. The area encompassed by and between these sites corresponds to the main area of commercial squid fishing. Oxygen profiles were determined over this area. () Site where the profile in Fig. 10 was determined. Depth contour labels are in meters. Bathymetry data for the main map at 2 min resolution (Smith \& Sandwell 1997) were obtained from the National Geophysical Data Center (www.ngdc.noaa. gov/mgg/image/2minrelief.html) and plotted using ArcGIS 9 (ESRI). Bathymetric contours for the Santa Rosalia inset range from 100 to $1100 \mathrm{~m}$ and are also based on our data obtained with a commercial-grade sounder (Furuno) during the course of this project

(according to onboard diagnostic features), Tag $7 \mathrm{did}$ not report to Argos for $7 \mathrm{~d}$, so its whereabouts during that period are unknown. The general drift of all floating tags in the present study tended to be towards the southeast (not illustrated).

\section{Diel differences in depths occupied by Dosidicus gigas}

Data from every successful PAT tag indicate that Dosidicus gigas spends much of its time at depths $>200 \mathrm{~m}$, primarily during daylight hours. These points are well illustrated by Tag 1, deployed in September 2001 (Fig. 3). Time-at-depth histograms (Fig. 3A) for day (local sunrise to sunset times) and night (sunset to sunrise) clearly have different peak values, with the peak of the nighttime distribution occurring at a much shallower depth. Time-at-temperature data (Fig. 3B) show that a large fraction of time is spent at temperatures of 10 to $14^{\circ} \mathrm{C}$, which characterizes the 200 to $300 \mathrm{~m}$ depth range (Fig. $3 \mathrm{C}$ ). Because the site where the tag surfaced and first reported to Argos was close to the deployment site (Fig. 2), it is likely that this squid remained in the immediate area of the Santa Rosalia fishing grounds during the $6 \mathrm{~d}$ it carried the tag. Maximum and minimum depths reached by the squid dur- ing each 2 h summary period are illustrated in Fig. 3D. Maximum depths during daytime hours ranged from about 250 to $300 \mathrm{~m}$. Sharp upward movements are evident just before dusk in both the maximum and minimum depth data.

Three additional tags were deployed in late October 2004 and confirmed the qualitative picture revealed by the 2001 experiment. Although there is individual variation in the time-at-depth distributions and in the degree of overlap between day and night, the diel difference in vertical distribution is evident by inspection of each data set (Fig. 4A-C) as well as in the overall mean data (Fig. 4D). Daytime mode was 350 to $400 \mathrm{~m}$ versus 100 to $200 \mathrm{~m}$ at night. Upward movements before dusk, as discussed in conjunction with Tag 1, occurred regularly (Fig. 5A). Similar results were obtained with 2 of 3 tags in November 2005 (Fig. 6, and see discussion of 2005 migration data below).

\section{Progressive changes in vertical distribution during southward migrations in 2004}

Squid fishing off Santa Rosalia is largely carried out along the 300 to $400 \mathrm{~m}$ depth contour, which corre- 

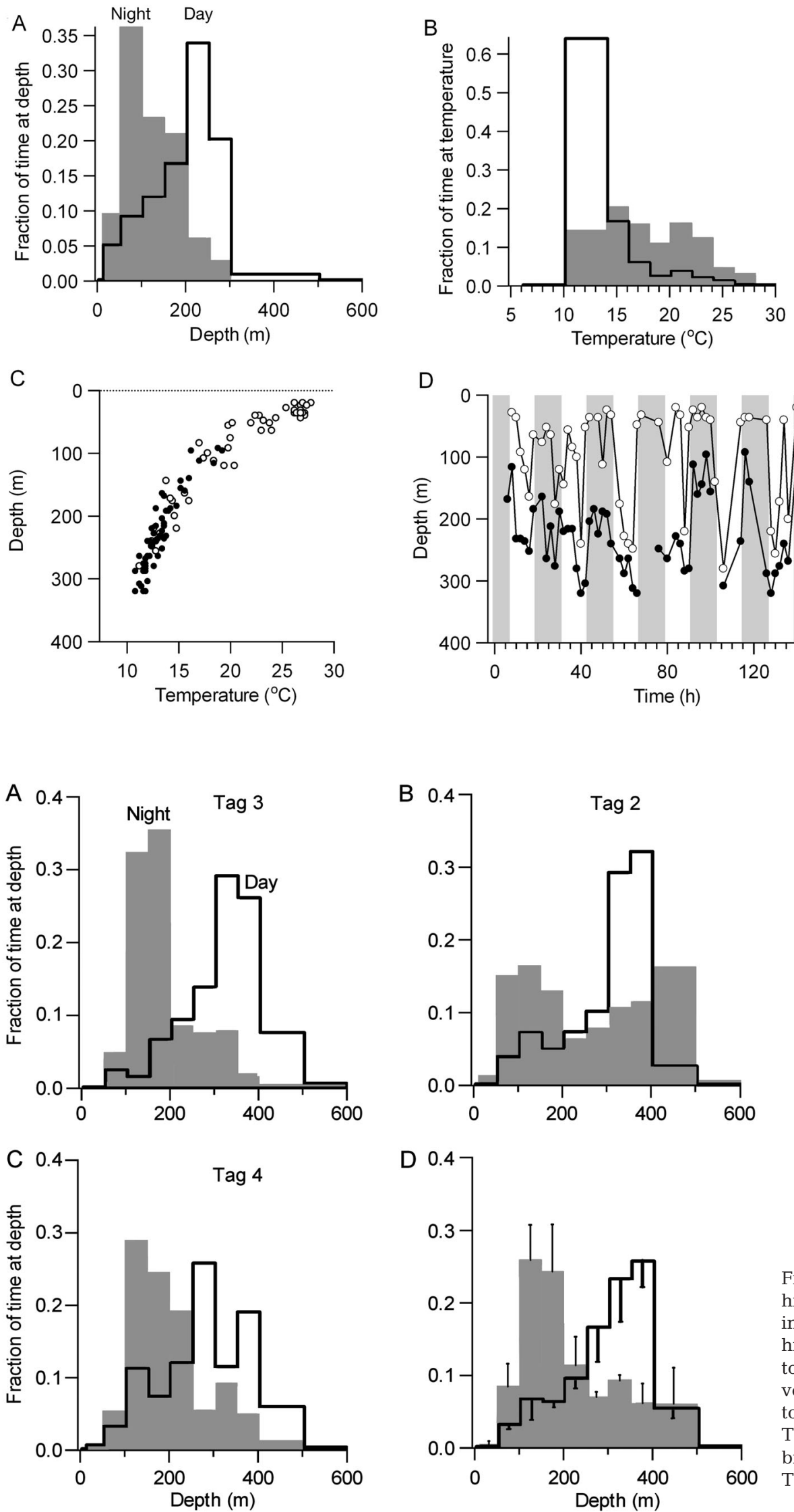

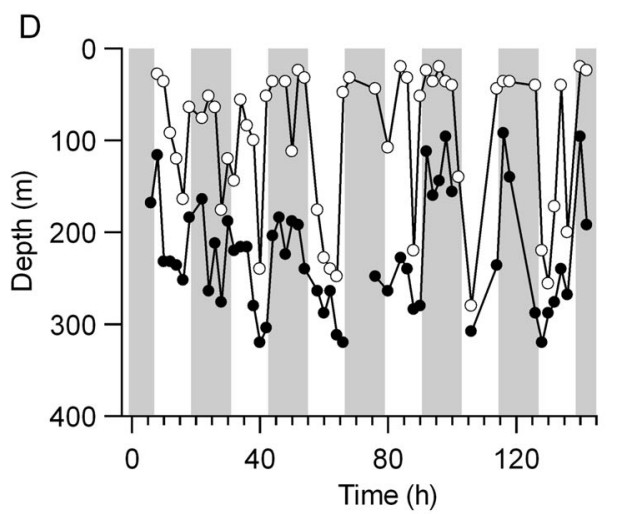

Fig. 3. Dosidicus gigas. Diel change in vertical distribution as revealed by PAT Tag 1 in September 2001. (A) Time-at-depth and (B) time-at-temperature histograms for daytime (open histogram) and nighttime (shaded histogram). (C) Overall temperature versus depth profile sample over the entire time of tagging. Each point represents the temperature recorded at the maximum (•) or minimum (O) depth encountered during a total of 52 2-h bins. (D) Maximum (•) and minimum (O) depths sampled in each 2 -h bin. Time zero is local midnight

Fig. 4. Dosidicus gigas. Time-at-depth histograms for the 3 PAT tags deployed in October 2004. Daytime data (open histogram); nighttime data (shaded histogram). All tags show a diel change in vertical distribution qualitatively similar to that illustrated in Fig. 3. Data for (A) Tag 3 computed from a total of 151 1-h bins, (B) Tag 2 from 148 1-h bins and (C) Tag 4 from 52 2-h bins. (D) Mean values for Tags 2-4. Error bars are SE 

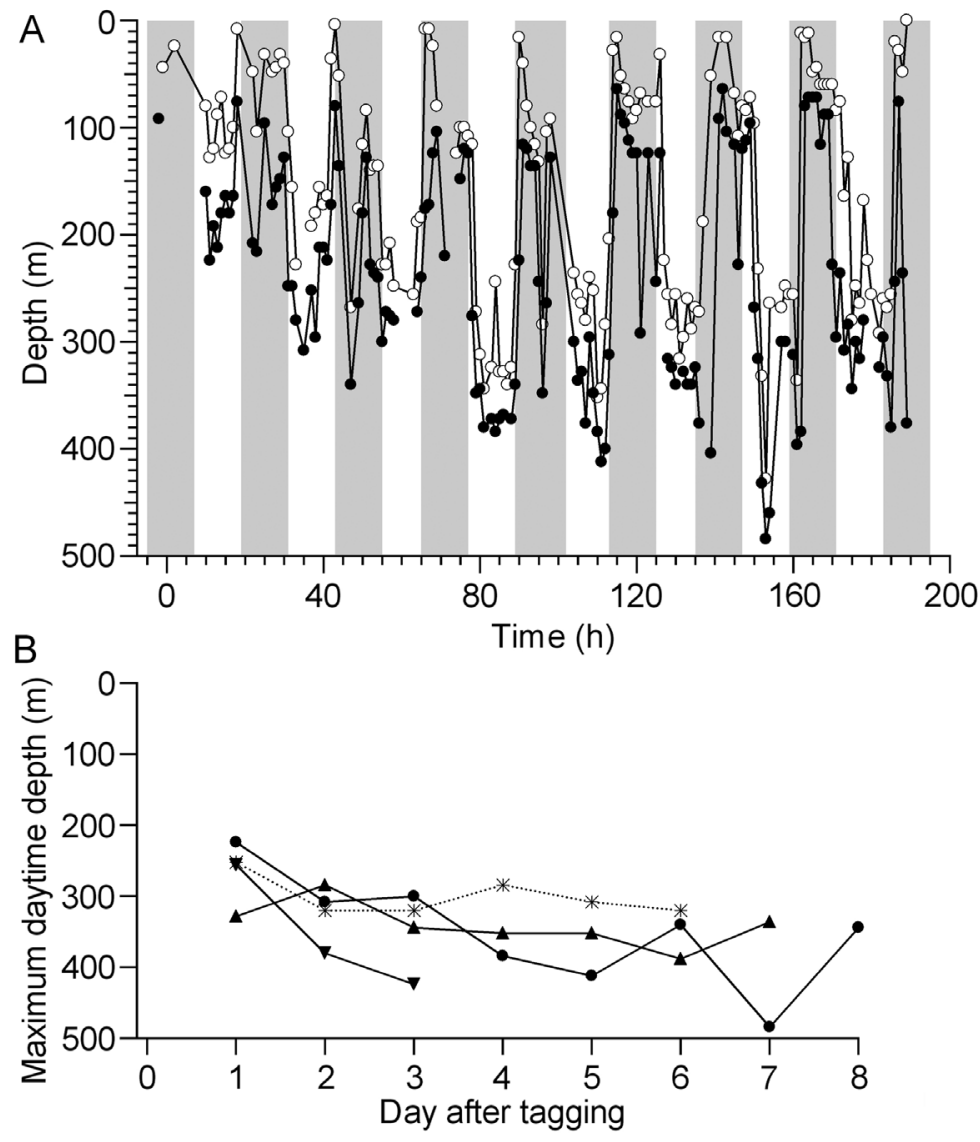

Fig. 5. Dosidicus gigas. Progressive increase in daytime depths during long-distance southward migrations. (A) Depth data for Tag 3 sampled in each hourly bin (•: maxima, o: minima) show that the squid increased its total vertical range of movement and reached greater depths as it moved away from Santa Rosalia into deeper waters of the open Gulf. Nighttime hours are shaded. Time zero is local midnight. (B) Maximum daytime depth increases over time for squid that migrated a long distance ( : Tag 4, $\bullet$ : Tag 3, $\mathbf{v}$ : Tag 2). This trend is not evident with the squid that remained in the Santa Rosalia area early in the fall of 2001 (Tag 1, dotted line) or in the $31 \mathrm{~d}$ of archival-tag data (see Fig. 7). This squid also appeared to remain in the local area during the time it was tagged

sponds to the western edge of a southward-running canyon between Isla San Marcos and the Baja peninsula (Fig. 2). Depth increases fairly rapidly eastward into the Guaymas Basin, and all of the tagged squid in 2004 (Tags 2 to 4) must have moved through this deeper area.

Examination of hourly maximum and minimum depth data reveals that in 2004 each squid tended to increase its total vertical range as it moved away from Santa Rosalia and out into the deeper waters of the Gulf. Fig. 5A illustrates this for Tag 3. Although the general trend of shallower at night and deeper during the day continued during the migration, the daytime depth range became progressively deeper, and after Day 3 almost all daytime activity occurred at depths
$>300 \mathrm{~m}$. A similar progressive deepening of daytime depths was evident in data from Tags 2 and 4 (Fig. 5B).

During the migrations, nighttime behavior was variable and showed no obvious trends. Data in Fig. 5A indicate that this squid (Tag 3) reached shallower nighttime depths during the migration, and a similar trend was seen with Tag 4 (not illustrated). Data from Tag 2 (not illustrated) were opposite in nature, as this squid engaged in unusually deep nighttime activity during Days 3 and 4, as shown in the time-at-depth data in Fig. 4B.

\section{Variability in vertical distribution during northward migrations in 2005}

Tags in 2005 were purposely deployed for short periods (3 d) because we planned to recover the tags after they surfaced in order to acquire the archival time-series data. However, this proved to be impossible because of the unexpectedly rapid and long migrations carried out by the squids and by strong winds which arose within $2 \mathrm{~d}$ after the deployments.

With only $3 \mathrm{~d}$ of accumulated data, it is difficult to ascertain any trend like that discussed above for 2004. One squid (Tag 7) did reach progressively deeper depths during its migration (Fig. 6A), but the endpoint location for this tag was ambiguous (see next paragraph). Both Tags 5 and 6 surfaced on schedule at a distance of 80 and $100 \mathrm{~km}$, respectively (Fig 2). Tag 6 showed the typical diel difference in vertical distribution with obvious upward migrations at dusk (Fig. 6B), but Tag 5 revealed an unusual pattern in which the squid remained in the 200 to $300 \mathrm{~m}$ range almost all the time (Fig. 6C) with only brief, modest upward migrations at dusk. Another feature common to the 2005 tags is the rapid and extreme increase in maximum depth achieved during the fourth night after tagging. In one case (Tag 6, Fig. 6B), the squid immediately returned to the pre-dive level near $100 \mathrm{~m}$, and the tag popped off shortly thereafter. In another (Tag 5, Fig. 6C) the tag somehow detached from the squid and floated to the surface, where it continued sampling until the scheduled release time. In the third case, Tag 7 (Fig. 6A) recorded $1000 \mathrm{~m}\left(4.4^{\circ} \mathrm{C}\right.$ ) as the last data set (depth off-scale in Fig. 6A) and then continued to record these values for $32 \mathrm{~h}$ before the tag released, based on the status report transmitted by Argos after the tag surfaced 7 d later. The status and location of the tag during those $7 \mathrm{~d}$ are unclear, since neither depth nor temperature were logged during this period. 

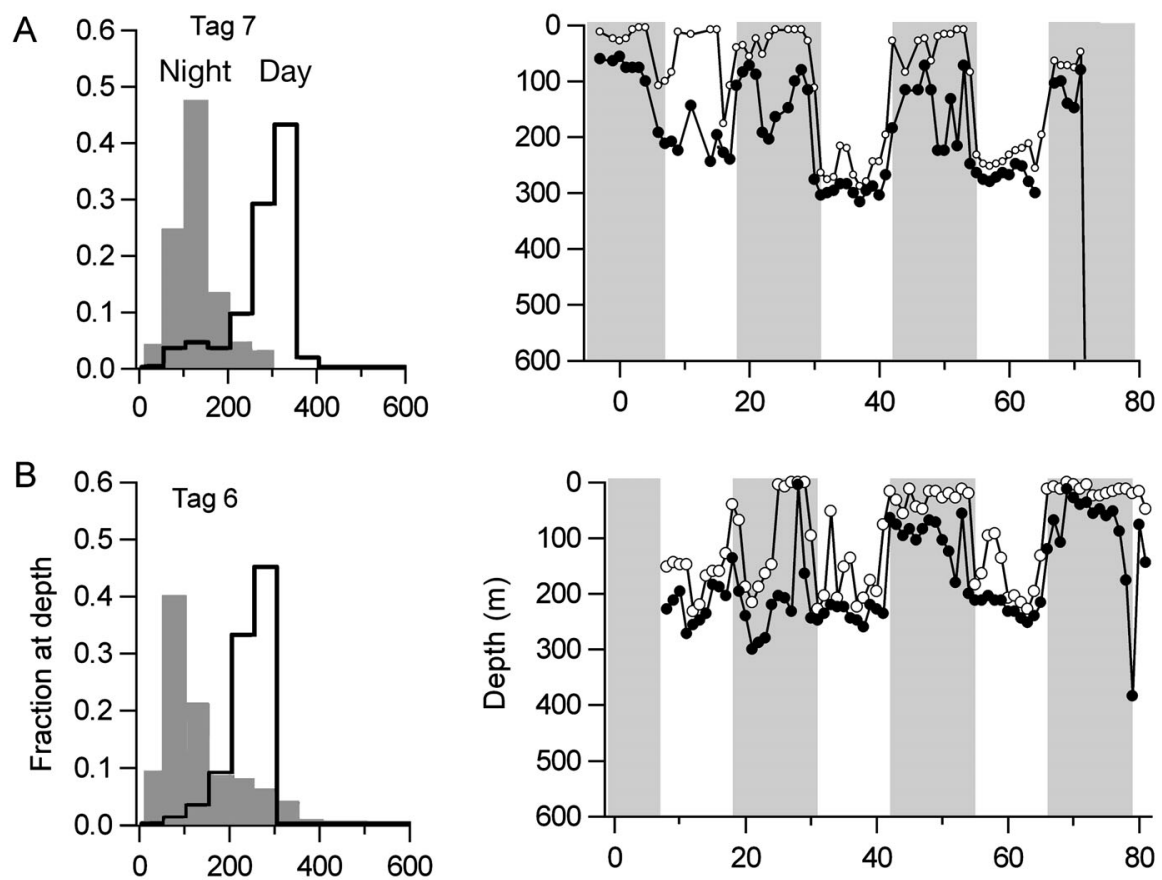

Fig. 6. Dosidicus gigas. Summary time-at-depth histograms (left panels) for daytime (open histogram) versus nighttime (shaded histogram) and the records of maximum $(\bullet)$ and minimum (o) depths over time (right panels) for the 3 PAT tags deployed in 2005. Nighttime hours are shaded in right panels. (A) Data for Tag 7 were computed from a total of 67
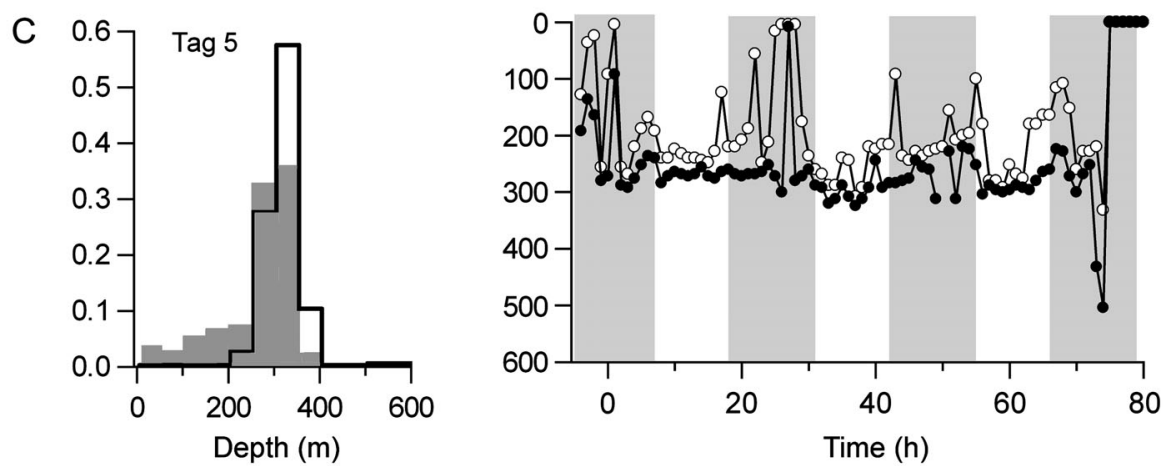

1-h bins. This squid behaved in a manner similar to those summarized in conjunction with Fig. 5. (B) Data for Tag 6 from 73 1-h bins. This squid did not move to progressively greater depths as it migrated. (C) Data from Tag 5 from 84 1-h bins. This squid showed virtually no diel change in vertical distribution and remained in the 200 to $300 \mathrm{~m}$ zone for most of its horizontal migration. Time zero for all panels is local midnight

It is not clear what such unusually deep excursions signify, but they may represent escape behavior due to predatory attacks. If so, the squid carrying Tag 6 presumably escaped successfully. Tag 5 may have released on schedule when the squid dove very deep, but the tag may well have been ripped off during an attack. The fate of Tag 7 is obscure, but the similarity of the deep excursion to the others is striking. If predatory attacks were behind these events, the identity of the predator and the coincidence in timing for all 3 squid are mysterious.

\section{Dynamics of vertical migrations}

Details of vertical migrations were directly revealed by $31 \mathrm{~d}$ of pressure and temperature data from an archival tag deployed off Santa Rosalia in September 2002 and recovered in the same area. The data pre- sented in Fig. 7 show that the squid tended to spend daylight hours at depths $>200 \mathrm{~m}$ and that it moved upward in the water column every day at dusk (and often downward at dawn). On some dates (mm/dd), all nighttime hours were spent at relatively shallow depths (e.g 9/28 and 10/1), but more commonly, rapid vertical movements back to typical daytime depths occurred (e.g. 9/29 and 9/30). In extreme cases, the squid returned to depth shortly after the upward dusk migration and remained deep for most or all of the night (e.g. 9/26 and 10/2). Daytime behavior was also highly variable. Sometimes the squid spent most of the day in a narrow depth range (e.g. 9/30 and 10/1), whereas on other days it engaged in much highfrequency diving (e.g. 10/3 and 10/4).

Vertical distributions derived from the archival data confirm a strong diel difference. Daytime data (Fig. 8A) are reasonably fit by a single Gaussian distribution $($ mean $\pm \mathrm{SD}=253 \pm 64 \mathrm{~m})$, but nighttime data are 

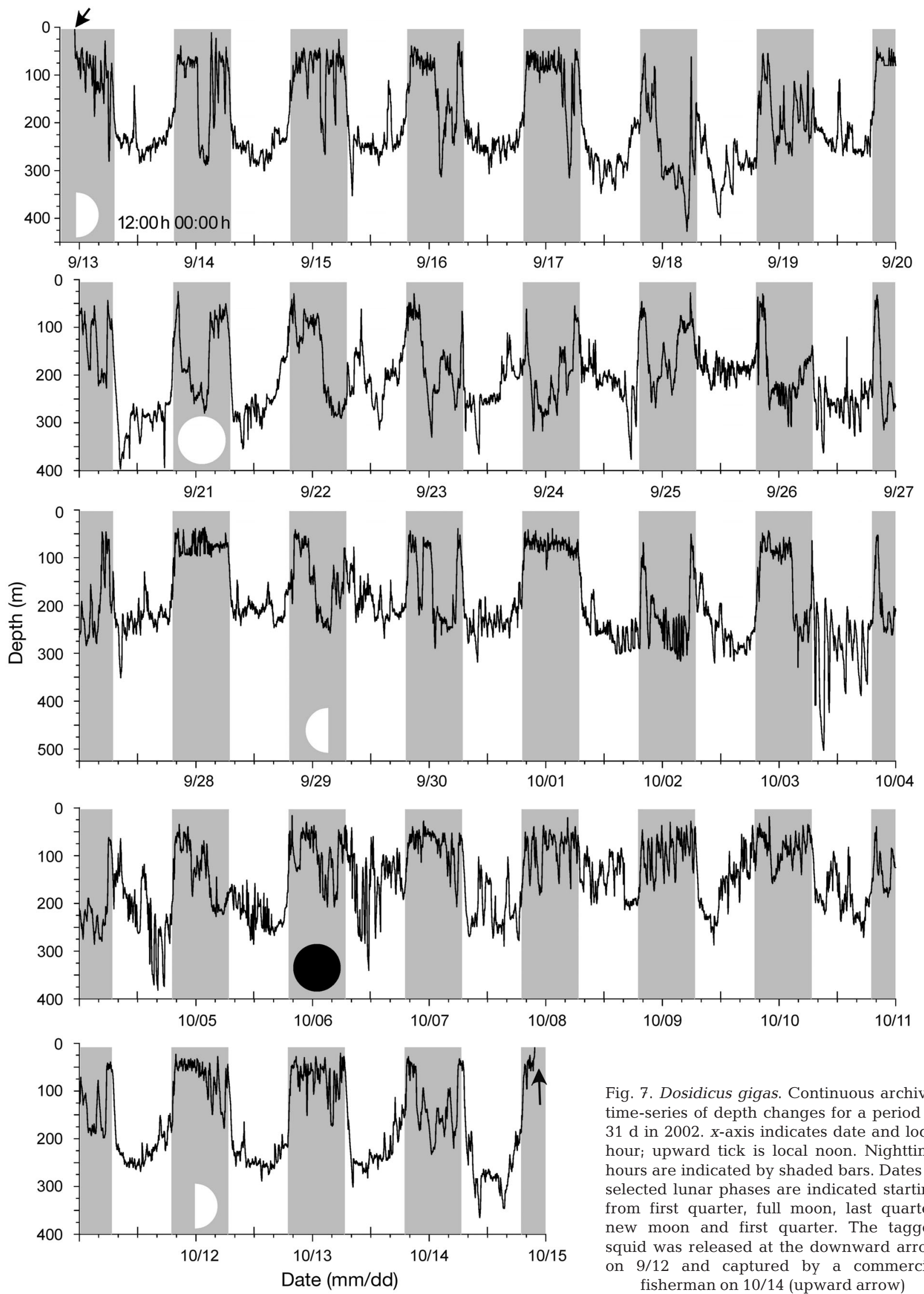

Fig. 7. Dosidicus gigas. Continuous archival time-series of depth changes for a period of $31 \mathrm{~d}$ in 2002. $\mathrm{x}$-axis indicates date and local hour; upward tick is local noon. Nighttime hours are indicated by shaded bars. Dates of selected lunar phases are indicated starting from first quarter, full moon, last quarter, new moon and first quarter. The tagged squid was released at the downward arrow on 9/12 and captured by a commercial fisherman on 10/14 (upward arrow) 

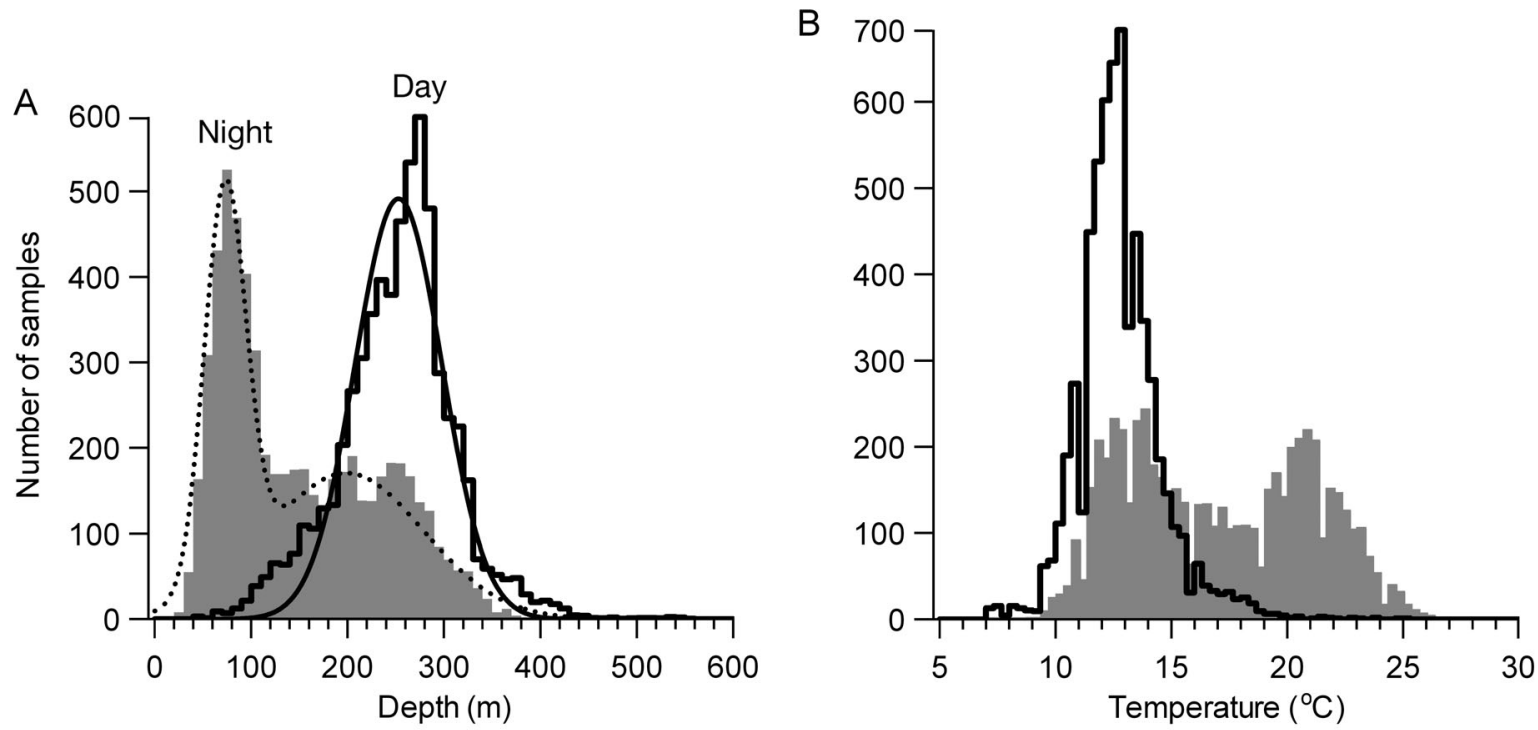

Fig. 8. Dosidicus gigas. Vertical distributions derived from 2002 archival tag data computed from all sampled data points (15 532). (A) Daytime data (open histogram) are fit reasonably well by a single, normal distribution (solid curve) with a mean of $253 \mathrm{~m}$ ( $\pm 64 \mathrm{SD})$. Nighttime data are clearly bimodal, and the dotted curve is the sum of 2 normal distributions with means $( \pm \mathrm{SD})$ of $73 \mathrm{~m}$ $( \pm 31)$ and $198 \mathrm{~m}( \pm 113)$. Fitting was performed using IgorPro V (Wavemetrics). (B) Corresponding temperature distributions for day (open) and night (shaded histogram)

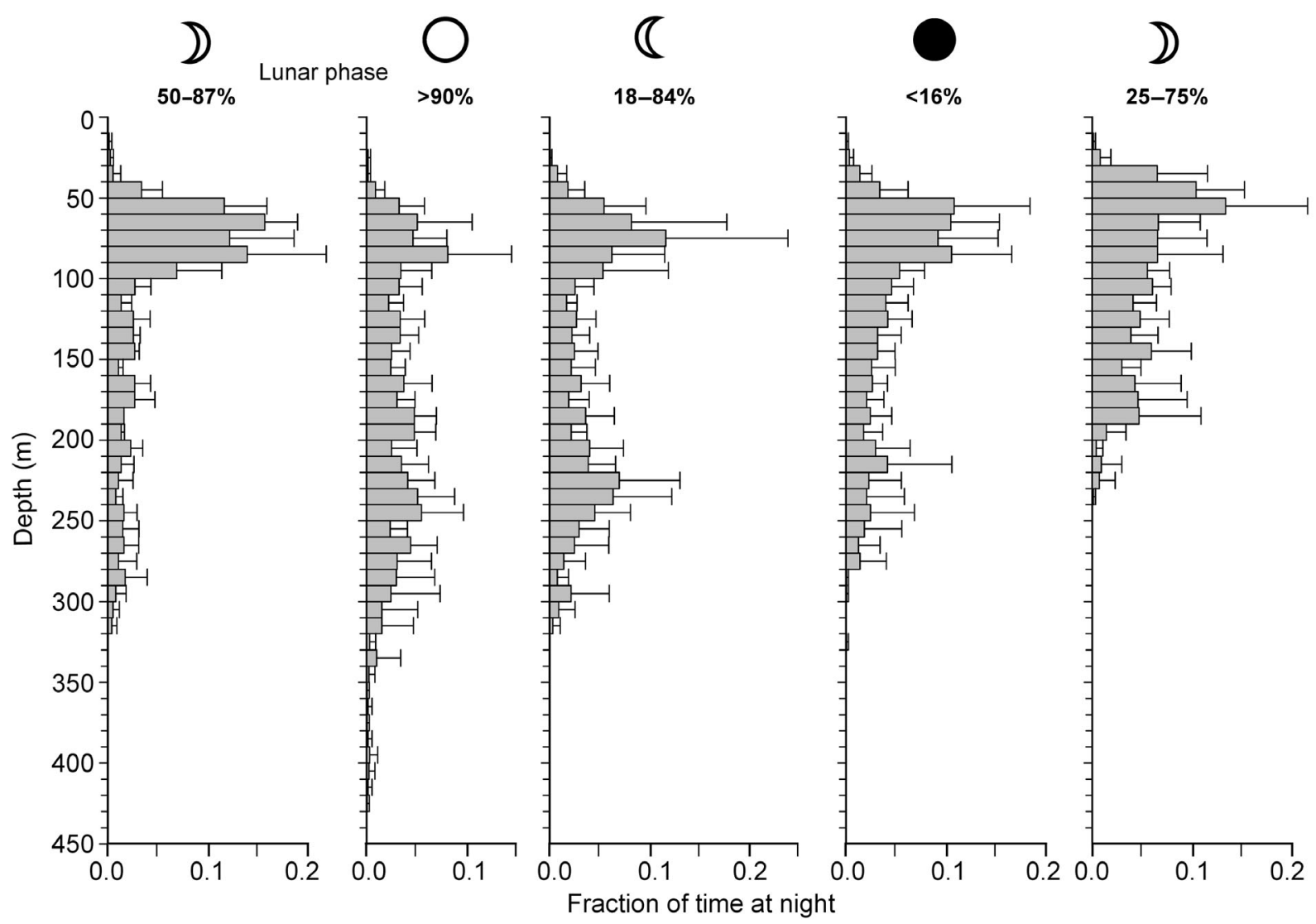

Fig. 9. Dosidicus gigas. Lunar influence on nighttime vertical distribution. Vertical distributions derived from the 2002 archival tag data were computed according to lunar phase. Nighttime fraction (mean \pm SD) for all nights of the indicated range of lunar phases was calculated for $10 \mathrm{~m}$ depth intervals. Lunar phases are (left to right): first quarter, full moon, last quarter, new moon and first quarter again. Moon percent illumination range is given below each lunar phase 
bimodal. The major nighttime component is shallow $(73 \pm 31 \mathrm{~m})$, with a deeper secondary peak $(198 \pm 113 \mathrm{~m})$ due to complex nighttime diving behavior. Temperature distributions are illustrated in Fig. $8 \mathrm{~B}_{\text {; }}$ as in the case of Tag 1 (Fig. 3C), the 10 to $14^{\circ} \mathrm{C}$ range characterizes the deep component in time-at-depth data.

Although there is considerable day-to-day behavioral variability (Fig. 7), particularly at night, data in Fig. 9 indicate a lunar influence on vertical migrations. During the period around the full moon, the shallow nighttime component of vertical distribution became less pronounced, whereas the deep nighttime component became more prominent. Average residence time above $100 \mathrm{~m}$ at night was significantly less during full moon than during other lunar phases (Mann-Whitney $U$-test, $\mathrm{p}<0.03$ ). During the period around the new moon, more nighttime activity occurred at shallower depths, and daytime diving activity appeared to be enhanced (10/3 to 10/8 in Fig. 7). The nighttime mode of 50 to $100 \mathrm{~m}$ was unchanged during this period.

\section{Vertical migrations and utilization of the oxygen minimum layer}

Depths below 200 to $300 \mathrm{~m}$ in the Gulf of California are generally associated with the OML, so the finding that the tagged jumbo squid spent the majority of their time at depths greater than $200 \mathrm{~m}$ is surprising. Oxygen versus depth profiles were measured in midNovember 2005 at 6 locations spread over the commercial fishing grounds off Santa Rosalia 1 to $2 \mathrm{~d}$ after deploying PAT Tags 5-7 in the same area (Fig. 2). All profiles were similar, and an example in Fig. 10 is compared to time-at-depth data for the archival-tagged squid. The average dissolved oxygen concentration at $200 \mathrm{~m}$ depth $(18.8 \pm 2.2 \mu \mathrm{M}$; mean $\pm \mathrm{SD}, \mathrm{n}=12)$ was about $10 \%$ of that at the surface $(185.2 \pm 5.7 \mu \mathrm{M})$. At $300 \mathrm{~m}$ depth, the oxygen level was $9.18 \pm 3.2 \mu \mathrm{M}$, less than $5 \%$ of that at the surface.

Despite low oxygen at 200 to $300 \mathrm{~m}$, the tag data indicate that Dosidicus gigas spends a large fraction of its time in this zone, which constitutes the upper boundary layer of the OML. In the case of the archivaltagged squid, the degree of diving activity in this hypoxic environment was comparable to that in shallower, well-oxygenated waters. This is true during both day- and nighttime (Fig. 11). In Fig. 11A most high-frequency diving activity occurred above $200 \mathrm{~m}$ at night, but in Fig. 11B, the opposite was the case. In some instances, there appeared to be little difference in the characteristics of diving behavior, regardless of when or where it was displayed - deep or shallow, night or day. This was particularly evident in data from 10/1 and 10/8 (Fig. 11C,D, respectively).

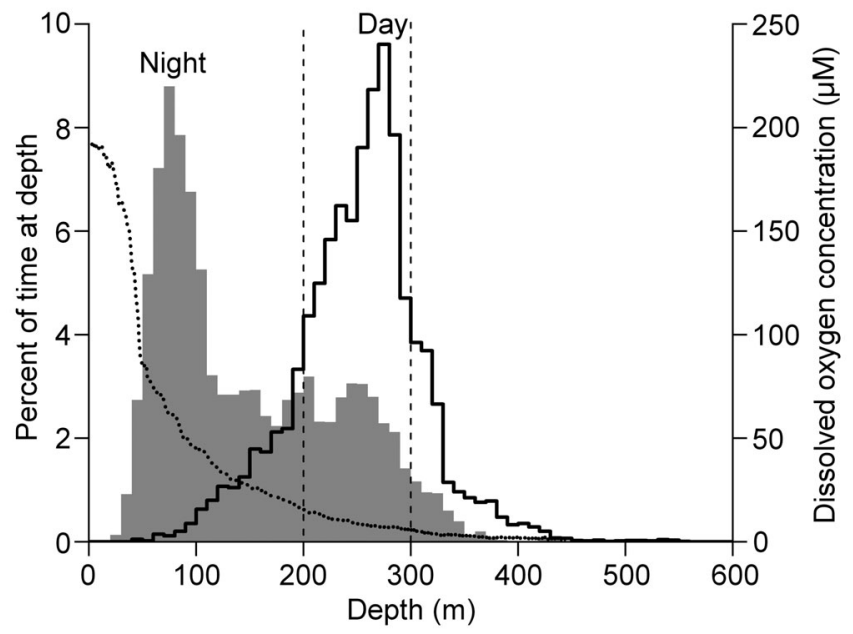

Fig. 10. Dosidicus gigas. Oxygen versus depth profile in relation to the vertical distribution of squid. Vertical distributions of squid are taken from Fig. 8. Dashed lines at 200 and $300 \mathrm{~m}$ indicate a hypoxic depth range that is heavily occupied by squid during both during daytime and nighttime hours

Although most dives took the squid into hypoxic depths of the OML for only a brief time, numerous long-lasting excursions into the OML also occurred (Fig. 12). The maximum duration below 200 and $300 \mathrm{~m}$ was nearly 800 and 400 min, respectively. Furthermore, during many of these long descents, the squid appeared to be quite active, with long bouts of highfrequency diving (Fig. 11B,C).

\section{Respiration rate of Dosidicus gigas and hypoxia tolerance}

Utilization of the OML by Dosidicus gigas indicates that this active and muscular squid can tolerate the hypoxic conditions presented by this midwater environment. We therefore measured the respiratory rate of $D$. gigas under laboratory conditions that mimicked the temperature and oxygen levels found in the OML. As indicated in Fig. 13A, respiration rate was well maintained until the dissolved oxygen level fell to $\sim 20 \mu \mathrm{M}$, a level $\sim 10 \%$ of saturation, but as oxygen was further depleted, the respiration rate fell dramatically. Oxygen consumption was measured over 3 ranges of oxygen concentration as illustrated in Fig. $13 \mathrm{~A}$ (high $=140$ to $220 \mu \mathrm{M} \mathrm{O}_{2}$ i medium $=50$ to $115 \mu \mathrm{M} ;$ low $=7.5$ to $14 \mu \mathrm{M})$, and a summary of all experiments is presented in Fig. 13B. Respiration rate at the lowest oxygen range was only $12 \%$ of the value at the highest range. This decrease in the rate of oxygen consumption at low oxygen levels was completely reversible on readmission of oxygenated water (Fig. 13A). 

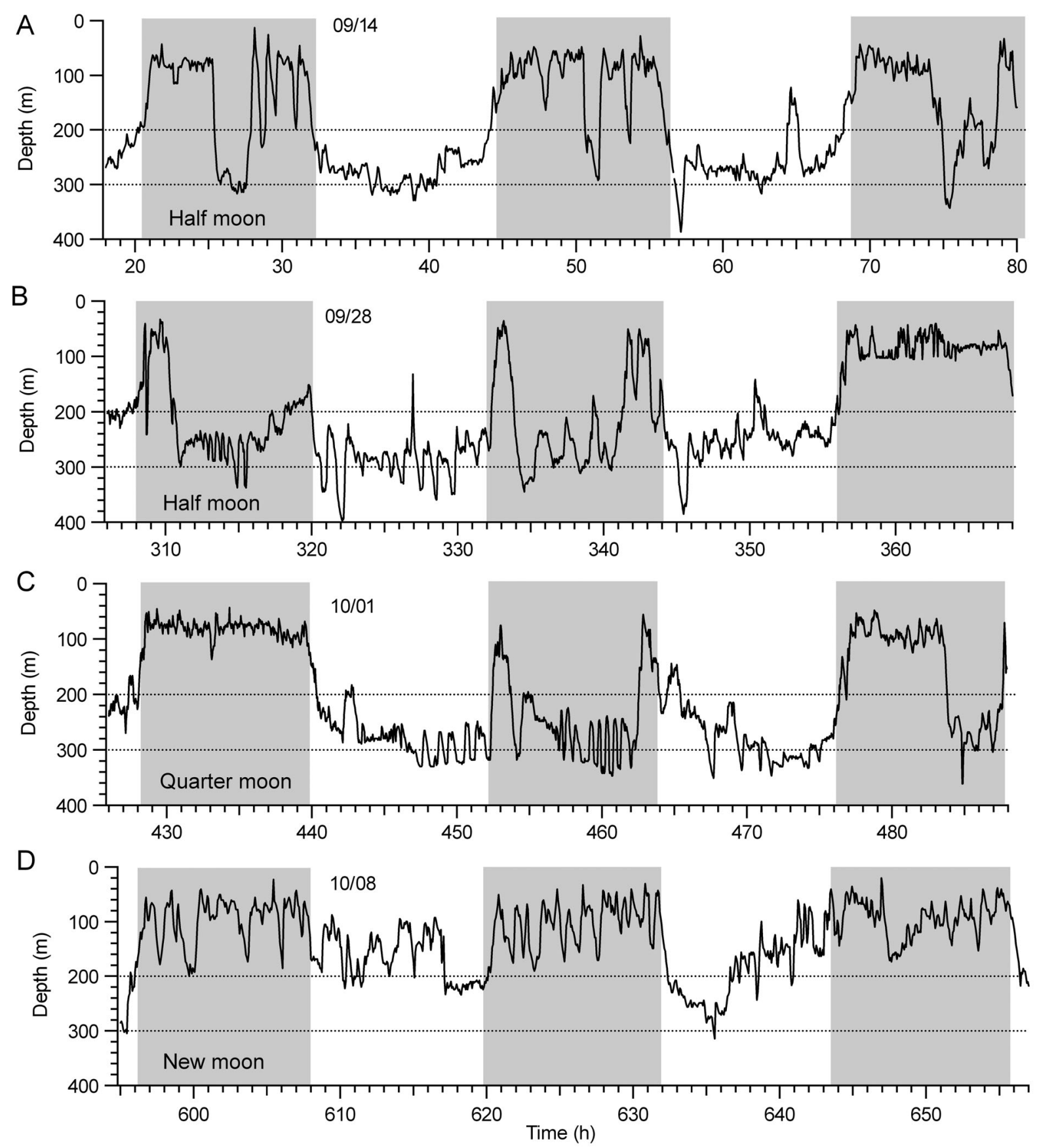

Fig. 11. Dosidicus gigas. Representative examples of diving dynamics. Selected segments of the depth time-series in Fig. 7 are plotted at higher temporal resolution to reveal high-frequency diving events. Nighttime hours indicated by shaded areas; approximate lunar phases indicated. Dates are mm/dd. The 200 to $300 \mathrm{~m}$ zone indicated by dotted lines. Much high-frequency diving occurs in this hypoxic zone. See text for additional details

\section{DISCUSSION}

Electronic tagging methods employed in this study shed new light on the biology of Dosidicus gigas, an ecologically and commercially important species in the eastern Pacific. We report on 3 sets of findings in this paper. (1) Long-distance horizontal migrations of D. gigas within the Gulf of California were revealed with satellite (PAT) tags. (2) A diel change in the overall vertical distribution of $D$. gigas was regularly observed that is similar to the migration of its primary prey, myctophid lanternfishes (Robison 1972, Markaida \& Sosa-Nishizaki 2003). But dynamics of vertical movements by $D$. gigas are far more complex than a simple diel migration, and, most 


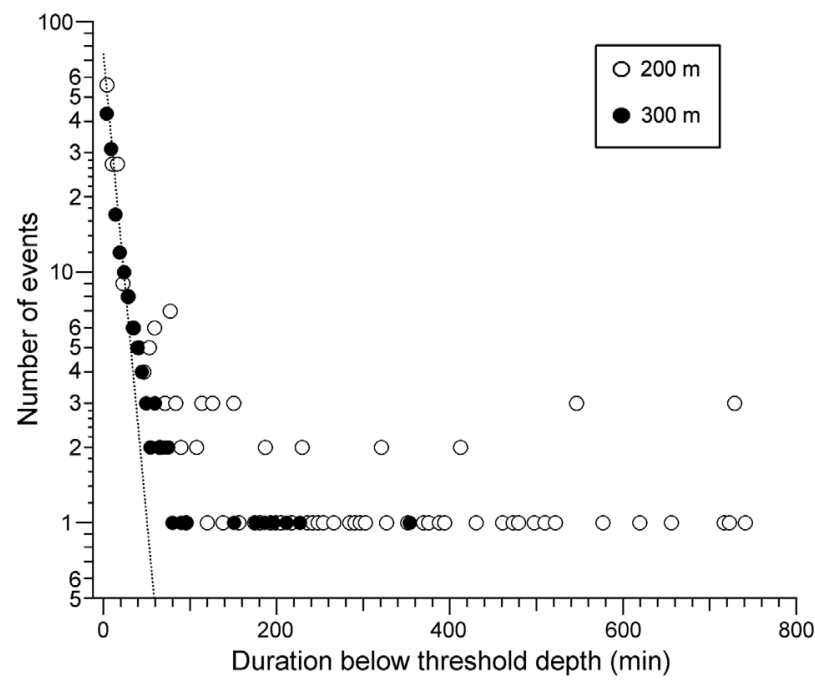

Fig. 12. Dosidicus gigas. Distribution of durations spent below threshold depth levels of $200 \mathrm{~m}(\mathrm{O})$ and $300 \mathrm{~m}(\bullet)$. The vertical log scale allows better resolution of the long descents. Dotted line represents an average dwell-time of 14.3 min spent below $200 \mathrm{~m}$ (fast component of a double exponential fit using Igor Pro 3.14, Wavemetrics)

surprisingly, this squid regularly penetrates the hypoxic environment of the OML. (3) Respirometry studies showed that $D$. gigas can greatly suppress its normally high rate of oxygen consumption when exposed to conditions similar to those found in the OML.

\section{Electronic tagging studies with squids}

Although satellite-linked and implanted archival tags of several types have been widely used with large pelagic fishes, mammals and diving birds (Naito 2004,
Block 2005, Ropert-Coudert \& Wilson 2005), the present study represents the first application of such devices to monitor long-term vertical migrations of a squid. Previous work (O'Dor 2002) was limited to relatively short studies (typically <2 d) with ship-based acoustic-tracking of Dosidicus gigas (Yatsu et al. 1999), of another ommastrephid, Ommastrephes bartramii (Nakamura 1991, 1993), and of a large loliginid, Loligo forbesi (O'Dor et al. 1994). Recently, archival tags have been employed in conjunction with acoustic tracking to study small-scale movements of a neritic cuttlefish, Sepia apama and another loliginid squid, Sepioteuthis lessoniana (Jackson et al. 2005).

Methods used in the present study are presently feasible only with large squid, so discussion of our results must be limited to adult Dosidicus gigas of $>75 \mathrm{~cm}$ ML. Juveniles or smaller individuals of this species (or other ommastrephids) may behave differently. In addition, all of our studies were carried out between September and November, and it is possible that significant seasonal differences exist in the behavior of $D$. gigas in the area of study.

Previous conventional tagging studies did not reveal deleterious effects of handling and tagging of larger Dosidicus gigas individuals (Markaida et al. 2005), but the strongest case for minimal short-term impacts of tagging may come from a squid tagged with a PAT device in November 2005 and recaptured on a jig by a commercial fisherman $1 \mathrm{~h}$ later. The recovered archival data (1 Hz sampling) confirm robust activity during the time between release and recapture, with several upward vertical excursions reaching $1 \mathrm{~m} \mathrm{~s}^{-1}$ and a downward jet of $0.7 \mathrm{~m} \mathrm{~s}^{-1}$ just prior to encountering the jig. These velocities indicate a healthy animal (see next section).
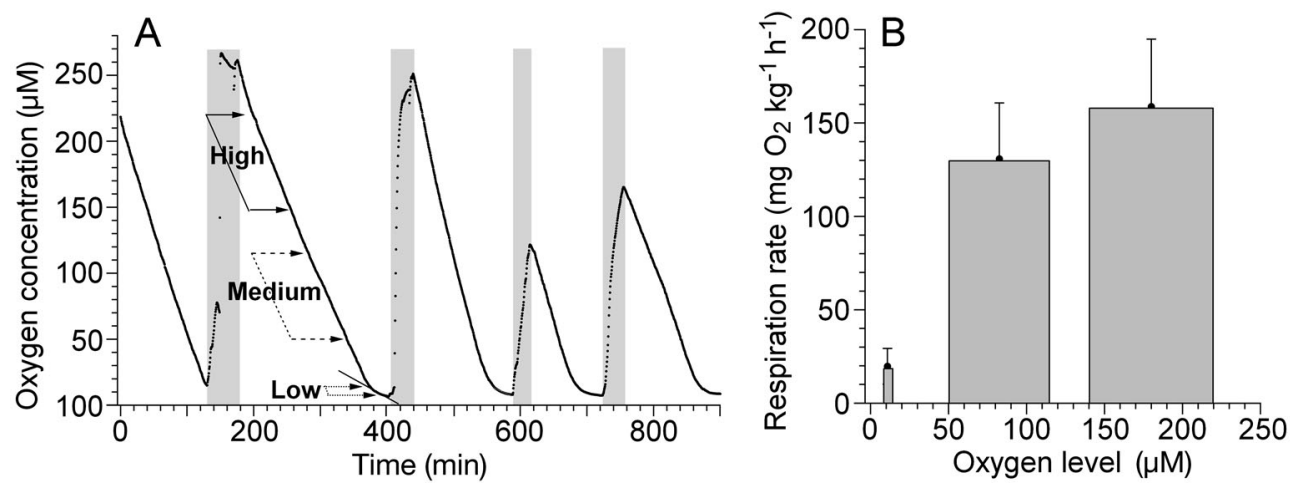

Fig. 13. Dosidicus gigas. Measurement of respiration rate. (A) Five different runs were carried out in order to measure the rate of oxygen consumption at 3 ranges of oxygen concentration (high, medium and low as labeled). During the periods indicated by the shaded areas, fresh oxygenated, chilled seawater was introduced into the tank. Rate of oxygen consumption was obtained by fitting straight lines to the data over the selected ranges of oxygen concentration. (B) Summary of the dependence of respiration rate on oxygen concentration in the seawater. Means (and SD) were computed from experiments on 3 squid with a total of 6 runs for the high oxygen, 10 runs for the intermediate, and 8 runs for the low level. A fourth squid was also studied (3 runs at high oxygen range only), with a similar result 


\section{Long-distance migrations in the Gulf of California}

Migrations of Dosidicus gigas within the Gulf of California have been previously demonstrated by conventional tag-and-recapture methods (Markaida et al. 2005). A migration from the fishing grounds off Santa Rosalia to those off Guaymas occurred in November at an average estimated velocity of $8 \mathrm{~km} \mathrm{~d}^{-1}$, with a reciprocal migration back to Santa Rosalia in May. Three PAT tags that released on schedule in the present study revealed much higher velocities. These squid moved over a straight-line distance of $\sim 200 \mathrm{~km}$ in $7 \mathrm{~d}$ (Tag 2) or $100 \mathrm{~km}$ in 3 to $4 \mathrm{~d}$ (Tags 5 and 6), consistent with an average migration rate of about $30 \mathrm{~km} \mathrm{~d}^{-1}$ $\left(0.35 \mathrm{~m} \mathrm{~s}^{-1}\right.$ or $\left.0.5 \mathrm{ML} \mathrm{s}^{-1}\right)$.

This value marks the upper end of the range of migration velocities reported for other species of squid ( 3 to $30 \mathrm{~km} \mathrm{~d}^{-1}$ : see Markaida et al. 2005, Stark et al. 2005), and should also be viewed in context with swimming velocities involved in other behaviors. Maximum velocity in the vertical direction measured by our longterm archival tag was $0.85 \mathrm{~m} \mathrm{~s}^{-1}(92 \mathrm{~m}$ in $108 \mathrm{~s})$ and $1.28 \mathrm{~m} \mathrm{~s}^{-1}(9 \mathrm{~m}$ in $7 \mathrm{~s})$ by the recovered PAT tag. Maximum jetting velocity of Dosidicus gigas is unknown, but it probably exceeds the $1.8 \mathrm{~m} \mathrm{~s}^{-1}$ value reported by Cole \& Gilbert (1970). Reports of sport fishermen in the Santa Rosalia area indicate adult jumbo squid can readily attack and catch a surface lure that is trolled at $3 \mathrm{~m} \mathrm{~s}^{-1}$ (A. and C. Brown pers. comm. to W.F.G.). Migration rates observed in the present study are thus considerably lower than maximum swimming velocity.

At least 2 of the 3 squid tagged in mid-November 2005 migrated to the northeast toward the San Pedro Martir Basin, an area which has been reported to be a mating and spawning location (Gilly et al. 2006). We therefore hypothesize that one migration route from Santa Rosalia to Guaymas involves passage through the San Pedro Martir area, and that the same route could be traveled in the opposite direction in May. This area marks the northern limit of the Gulf's welldeveloped OML (Roden 1964, Alvarez-Borrego \& Lara-Lara 1991). Moreover, the seasonal squid migrations match a seasonal current that changes direction at about the same time of year (Alvarez-Borrego 2002). This current could serve to both guide and ease migrations.

Variability clearly exists in the exact direction of this northward migration. Squid tagged within hours of each other at the same place (Tags 5 and 6) did not migrate to the same distant location several days later. Thus, Dosidicus gigas does not appear to migrate en masse. Instead, assemblages are likely to be fairly small and independently mobile. This idea is consistent with observations of $D$. gigas made in the Gulf of California by a remotely operated vehicle, ROV (B.
Robison unpubl. data). Variability in vertical distribution was also found for migrating squid in 2005 (e.g. Tag 5 vs 6), but it is unknown if this reflects differences between individual squid or between small schools.

A large difference in migration pathways was observed between the 2005 tags discussed above and those deployed in late October 2004, specifically Tags 2 and 4 . Variability between squid is harder to assess here, because only one tag released on schedule, but again it seems that considerably different paths were followed. Obviously, a southern migration arc could also lead some squid toward Guaymas, but the long distance involved makes this seem unlikely. Because this species is present throughout the southern Gulf and in the neighboring Pacific Ocean, we propose that some squid migrate southward to other areas of the Gulf that are presently not subject to commercial fishing, or out of the Gulf entirely and into the Pacific.

Although comparing results from squid tagged in different years is problematic, we believe that well established seasonal effects of prevailing winds and sea surface temperatures in this part of the Gulf in late autumn are the major factors influencing migrations. We are not aware of any long-term oceanographic changes in the Guaymas Basin during the course of our study.

\section{Vertical migrations and utilization of the oxygen minimum layer}

Diel vertical migrations are common among the ommastrephid squids (Roper \& Young 1975). Dosidicus gigas feeds heavily on myctophid fishes and other mesopelagic fauna that constitute the acoustic DSL (Markaida \& Sosa-Nishizaki 2003), an assemblage that shows a pronounced diel vertical migration (Robison 1972). In the region around Santa Rosalia, the DSL typically lies in the 200 to $300 \mathrm{~m}$ range during the day (Dunlap 1970, authors' unpubl. data), which is also the upper boundary of the OML and the predominant daytime location of $D$. gigas (Fig. 10).

We assume that most of the high-frequency diving behavior (particularly the rhythmic episodes) displayed by $D$. gigas during the night represents foraging (Figs. 11B-D). Characteristics of daytime activity are similar, and we therefore propose that $D$. gigas also forages during daylight hours at depths characteristic of the OML. Direct observations of daytime feeding within the OML have been made in the Guaymas Basin and elsewhere in the Gulf using an ROV (B. Robison \& K. Reisenbichler unpubl. data). This capability of potentially continuous feeding would be highly advantageous for an organism with a growth rate as high as that of $D$. gigas $\left(1 \mathrm{~mm} \mathrm{~d}^{-1} \mathrm{ML}\right.$ at adult size; Markaida et al. 2005). 
Although a squid may reliably rise towards the surface at every sunset (Fig. 7), it clearly does not always remain there throughout the night. Rapid transient descents of 100 to $200 \mathrm{~m}$ often occurred at night (Fig. 11A), but the purpose of these dives is unclear. They may represent escape responses from predators, which in the study area would most likely be sperm whales (Jaquet \& Gendron 2002), or they could be recovery dives to alleviate physiological stress incurred during active foraging in extremely warm surface waters. In some cases the squid remained near the surface only a short time after dusk, and then moved back to the 200 to $300 \mathrm{~m}$ zone in the OML, where it engaged in rhythmic bouts of diving that we associate with foraging (Fig. 11B). In other cases, such rhythmic diving was limited to the 100 to $200 \mathrm{~m}$ zone (Fig. 11C).

These data suggest that Dosidicus gigas, an opportunistic predator, actively searches for a depth that is rich in prey and then exploits that zone. Productive zones are likely to be ephemeral and depend on environmental factors such as lunar phase (Fig. 9) that more directly influence the movements of the fauna which comprise the DSL (Boden \& Campa 1967, Gliwicz 1986, Tarling et al. 1999, HernandezLeon et al. 2002). Given the migratory capabilities of this squid, extension of such a search strategy to the horizontal dimensions is likely. For example, squid near Santa Rosalia appear to rise from deep in the local canyon at dusk and move into the shallower inshore areas where they are commercially fished (Fig. 2, W.F.G. \& U.M. unpubl. obs.).

\section{Hypoxia tolerance and utilization of the oxygen minimum layer}

Much of the putative foraging discussed above occurs below $300 \mathrm{~m}$ depth, where the oxygen concentration is $<5 \%$ of the value at the surface (Fig. 10). This presents a challenge to an active predator with a high rate of aerobic metabolism. Our measurements for Dosidicus gigas yield a standard aerobic metabolic rate (equivalent to that at zero swimming velocity in a fish) of $>150 \mathrm{mg} \mathrm{O}_{2} \mathrm{~kg}^{-1} \mathrm{~h}^{-1}$ at 6 to $7^{\circ} \mathrm{C}$, a value comparable to those for active pelagic fishes such as tuna at a similar temperature (Dewar \& Graham 1994). Squid maintained this high rate until dissolved oxygen fell to about $10 \%$ of saturation, but as oxygen fell further, the rate of oxygen consumption was reversibly suppressed by $90 \%$. This ability of $D$. gigas is remarkable, given the hypoxia intolerance displayed by other active, muscular squids, including ommastrephids (Webber et al. 2000, Zielinski et al. 2000, Pörtner 2002). Metabolic suppression has been reported in some mesopelagic cephalopods, but these are relatively weak and slow-moving forms (Childress \& Seibel 1998).

Although metabolic suppression is likely to be relevant to the ability of Dosidicus gigas to tolerate the hypoxic OML, it cannot be the only mechanism involved, because activity levels revealed by tagging appear to remain remarkably high. Most descents below 200 to $300 \mathrm{~m}$ lasted for less than $30 \mathrm{~min}$, and this may be relevant to avoiding anoxia. But a substantial number of descents lasted for many hours (Fig. 12), during which time rhythmic diving occurred that appeared to be as robust as that observed at well oxygenated, shallower depths (Fig. 11B,C).

Long-distance migratory behavior displayed by a squid tagged in 2005 (Fig. 6C) also points to a high level of activity under hypoxic conditions. This squid spent only $\sim 10 \%$ of its time at depths shallower than $200 \mathrm{~m}$ during a period of $3 \mathrm{~d}$ in which it migrated at least $80 \mathrm{~km}$. Only 27 of the 781 -h depth minima were $<200 \mathrm{~m}$. It is thus likely that this squid was quite active under hypoxic conditions during much of this $3 \mathrm{~d}$ period. Although we did not measure oxygen profiles over the deeper basins of the Gulf, a 250 to $300 \mathrm{~m}$ figure for the upper boundary of the OML is consistent with available oceanographic data (Alvarez-Borrego \& Lara-Lara 1991, B. Robison \& K. Reisenbichler unpubl. data).

Physiological and biochemical adaptations that allow Dosidicus gigas to remain active under hypoxic conditions are unknown, but it is clear that a strong association between this species and the OML exists. Such an association is reflected in the geographical distribution of the species which is similar to that of the OML (Deuser 1975) and to the phosphorus isopleth of $0.8 \mathrm{mg} \mathrm{m}^{-3}$ at 0 to $100 \mathrm{~m}$ depth (Nigmatullin et al. 2001). Both of these oceanographic features correlate with high surface productivity. The ability to forage in the rich near-surface waters that ultimately cause the OML, as well as within the OML itself, would be highly advantageous to a fast-growing predator like $D$. gigas. Additional benefits would include reduced competition with, and protection from, pelagic fish predators that cannot tolerate such hypoxic conditions. Predator avoidance would undoubtedly be particularly important for juveniles and smaller $D$. gigas individuals if they also utilize the OML as the adults do.

An association between a 'giant' form of Sthenoteuthis oualaniensis (a species closely related to Dosidicus gigas; our unpubl. genetic analysis) and the OML in the Arabian Sea has also been noted (Nesis 1993). Physiological mechanisms underlying this ability may thus allow both D. gigas and S. oualaniensis (Shulman et al. 2002) to thrive in an environment that is generally not favored by most large pelagic fishes or even other large cephalopods. 
Acknowledgements. We are grateful to Kevin Weng for help with the initial phase of this tagging program, Jason Blank for early inspiration with respirometry experiments, Steve Teo for tag programming, Robyn Matteson for data analysis, Ashley Booth for GIS mapping, and Allen and Christine Brown for information on squid swimming speed. We acknowledge Brad Seibel for many useful discussions on hypoxia tolerance and thank the crew and other scientists during our cruises on the RV 'Western Flyer' as well as John and Joanne Barnes for their efforts on the RV 'Marylee'. We thank Oscar Sosa-Nishizaki for administering and supporting this project in Mexico, and Sandra Patricia Garaizar and Vicente Monreal for assistance with tag recoveries. We are deeply indebted to Cipriano Rojas, the fisherman who recovered the archival tag. This work was supported the National Science Foundation (Grant no. OCE 0526640), the David and Lucile Packard Foundation, the National Geographic Society (Grant no. 7578-04), and by the Gordon and Betty Moore Foundation through the Census of Marine Life project, Tagging of Pacific Pelagics (TOPP).

\section{LITERATURE CITED}

Abitia-Cárdenas L, Muhlia-Melo A, Cruz-Escalona V, GalvánMagaña F (2002) Trophic dynamics and seasonal energetics of striped marlin Tetrapturus audax in the southern Gulf of California, Mexico. Fish Res 57:287-295

Alvarez-Borrego S (2002) Physical oceanography. In: Case, TJ, Cody ML , Ezcurra E (eds) A new island biogeography of the Sea of Cortes. Oxford University Press, Oxford, p 41-59

Alvarez-Borrego S, Lara-Lara JR (1991) The physical environment and productivity of the Gulf of California. In: Dauphin JP, Simoneit B (eds) The Gulf and peninsular province of the Californias. Am Assoc Pet Geol Mem 47:555-567

Block BA (2005) Physiological ecology in the 21st centuryadvancements in bio-logging science. Integr Comp Biol 45:305-320

Boden BP, Campa EM (1967) The influence of natural light on the vertical migrations of an animal community in the sea. Symp Zool Soc Lond 19:15-26

Childress JJ, Seibel BA (1998) Life at stable low oxygen levels: adaptations of animals to oceanic oxygen minimum layers. J Exp Biol 201:1223-1232

Cole KS, Gilbert DL (1970) Jet propulsion of squid. Biol Bull (Woods Hole) 138:245-246

Deuser WG (1975) Reducing environments. In: Riley JP, Skirrow G (eds) Chemical oceanography, 2nd edn. Academic Press, New York, p 1-37

Dewar H, Graham JB (1994) Studies of tropical tuna swimming performance in a large water tunnel. I. Energetics. J Exp Biol 192:13-31

Dunlap CR (1970). A reconnaissance of the deep scattering layers in the eastern tropical Pacific and the Gulf of California. In: Farquhar GB (ed) Proc Int Symp on Biological Sound Scattering in the Ocean, Airlie House Conference Center, Warrenton, VA, March 31-April 2, 1970. Maury Center for Ocean Science, Report 005, Washington, DC, p 395-408

Ehrhardt NM (1991) Potential impact of a seasonal migratory jumbo squid (Dosidicus gigas) stock on a Gulf of California sardine (Sardinops sagax caerulea) population. Bull Mar Sci 49:325-332

Gilly WF, Elliger CA, Salinas CA, Camarillo-Coop S, Bazzino G, Beman M (2006). Spawning by jumbo squid Dosidicus gigas in the San Pedro Martir Basin, Gulf of California, Mexico. Mar Ecol Prog Ser 313:125-133

Gliwicz ZM (1986) A lunar cycle in zooplankton. Ecology 67:883-897

Hernandez-Leon S, Almeida C, Yebra L , Aristegui J (2002) Lunar cycle of zooplankton biomass in subtropical waters: biogeochemical implications. J Plankton Res 24:935-939

Ichii $\mathrm{T}$, Mahapatra $\mathrm{K}$, Watanabe $\mathrm{T}$, Yatsu A, Inagake $\mathrm{D}$, Okada Y (2002) Occurrence of jumbo flying squid Dosidicus gigas aggregations associated with the countercurrent ridge off the Costa Rica Dome during $1997 \mathrm{El}$ Niño and 1999 La Niña. Mar Ecol Prog Ser 231:151-166

Jackson GD, O'Dor RK, Andrade Y (2005) First tests of hybrid acoustic/archival tags on squid and cuttlefish. Mar Freshw Res 56:425-430

Jaquet N, Gendron D (2002) Distribution and relative abundance of sperm whales in relation to key environmental features, squid landings and the distribution of other cetacean species in the Gulf of California, Mexico. Mar Biol 141:591-601

Klimley AP, Caberera-Mancilla I, Castillo-Geniz JL (1993) Horizontal and vertical movements of the scalloped hammerhead shark, Sphyrna lewini, in the southern Gulf of California, Mexico. Cienc Mar 19:95-115

Markaida U, Sosa-Nishizaki O (2001) Reproductive biology of jumbo squid Dosidicus gigas in the Gulf of California, 1995-1997. Fish Res 54:63-82

Markaida U, Sosa-Nishizaki O (2003) Food and feeding habits of jumbo squid Dosidicus gigas (Cephalopoda: Ommastrephidae) from the Gulf of California, Mexico. J Mar Biol Assoc UK 83:507-522

Markaida U, Quiñónez-Velázquez C, Sosa-Nishizaki O (2004) Age, growth and maturation of jumbo squid Dosidicus gigas (Cephalopoda: Ommastrephidae) from the Gulf of California, Mexico. Fish Res 66:31-47

Markaida U, Rosenthal JJC, Gilly WF (2005) Tagging studies on the jumbo squid (Dosidicus gigas) in the Gulf of California, Mexico. Fish Bull 103:219-226

Naito Y (2004) Bio-logging science. Mem Natl Inst Polar Res Spec Iss 58:118-132

Nakamura, Y (1991) Tracking of the mature female of flying squid, Ommastrephes bartramii, by an ultrasonic transmitter. Bull Hokkaido Natl Fish Res Inst 55:205-208

Nakamura Y (1993) Vertical and horizontal movements of mature females of Ommastrephes bartramii observed by ultrasonic telemetry. In: Okutani T, O'Dor R, Kubodera T (eds) Recent advances in cephalopod fisheries biology. Tokai University Press, Tokyo, p 331-336

Nesis KN (1993) Population structure of oceanic ommastrephids, with particular reference to Sthenoteuthis oualaniensis: a review. In: Okutani T, O'Dor RK, Kubodera T (eds) Recent advances in cephalopod fisheries biology. Tokai University Press, Tokyo, p 375-383

Nigmatullin CM, Nesis KN, Arkhipkin AI (2001) A review on the biology of the jumbo squid Dosidicus gigas. Fish Res 54:9-19

O'Dor RK (2002) Telemetered cephalopod energetics: swimming, soaring and blimping. Integr Comp Biol 42: 1065-1070

O'Dor RK, Hoar JA, Webber DM, Carey FG, Tanaka S, Martins HR, Porteiro FM (1994) Squid (Loligo forbesi) performance and metabolic rates in nature. Mar Freshw Behav Physiol 25:163-177

Pörtner HO (2002). Environmental and functional limits to muscular exercise and body size in marine invertebrate athletes. Comp Biochem Physiol A 133:303-321

Robison BH (1972) Distribution of midwater fishes of the Gulf 
of California. Copeia 3:448-461

Roden GI (1964) Oceanographic aspects of Gulf of California. In: van Andel TH, Shor GG Jr (eds) Proc Symp Marine Geology of the Gulf of California. Am Assoc Pet Geol Mem 3:59-75

Roper CFE, Young RE (1975) Vertical distribution of pelagic cephalopods. Smithson Contrib Zool 209:1-51

Ropert-Coudert Y, Wilson RP (2005) Trends and perspectives in animal-attached remote sensing. Front Ecol Environ 3:437-444

Rosas-Aloya J, Hernández-Herrera A, Galván-Magaña F, Abitia-Cárdenas L, Muhlia-Melo A (2002) Diet composition of sailfish (Istiophorus platypterus) from the southern Gulf of California, Mexico. Fish Res 57:185-195

Ruiz-Cooley RI, Gendron D, Aguíñiga S, Mesnick S, Carriquiry JD (2004) Trophic relationships between sperm whales and jumbo squid using stable isotopes of $\mathrm{C}$ and $\mathrm{N}$. Mar Ecol Prog Ser 277:275-283

Shulman GM, Chesalin MV, Abolmasova GI, Yuneva TV, Kidneys A (2002) Metabolic strategy in pelagic squid of genus Sthenoteuthis (Ommastrephidae) as the basis of high abundance and productivity. An overview of the Soviet investigations. Bull Mar Sci 71:815-836

Smith WHF, Sandwell DT (1997) Global sea floor topography from satellite altimetry and ship depth soundings. Science 277:1956-1962

Editorial responsibility: Howard Browman (Associate Editorin-Chief), Storebø, Norway
Stark KE, Jackson GD, Lyle JM (2005) Tracking arrow squid movements with an automated acoustic telemetry system. Mar Ecol Prog Ser 299:167-177

Tarling GA, Buchholz F, Matthews JBL (1999) The effect of a lunar eclipse on the vertical migration behavior of Meganyctiphanes norvegica (Crustacea:Euphausiacea) in the Ligurian Sea. J Plankton Res 21(8):1475-1488

Teo SLH, Boustany A, Blackwell S, Walli A, Weng K, Block BA (2004) Validation of geolocation estimates based on light level and sea surface temperatura from electronic tags. Mar Ecol Prog Ser 283:81-98

Waluda CM, Rodhouse PG (2006) Remotely sensed mesoscale oceanography of the Central Eastern Pacific and recruitment variability in Dosidicus gigas. Mar Ecol Prog Ser 310: 25-32

Webber DM, Aitken JP, O'Dor RK (2000) Cost of vertical locomotion and vertical dynamics of cephalopods and fish. Physiol Biochem Zool 73:651-662

Yatsu A, Yamanaka K, Yamashiro C (1999) Tracking experiments of the jumbo flying squid Dosidicus gigas, with an ultrasonic telemetry system in the eastern Pacific Ocean. Bull Natl Res Inst Far Seas Fish 36:55-60

Zielinski S, Lee PG, Pörtner HO (2000) Metabolic performance of the squid Lolliguncula brevis during hypoxia: an analysis of the critical $\mathrm{PO}_{2}$. J Exp Mar Biol Ecol 243: 241-259

Submitted: June 28, 2006; Accepted: September 26, 2006 Proofs received from author(s): October 15, 2006 